\title{
Pelatihan Ahli Refrigerasi Tingkat 1 Bagi Para Guru dan Siswa SMK NEGERI 3 Pariaman
}

\author{
Roswati Nurhasanah $^{1}$; Prayudi $^{2}$; Suhengki ${ }^{3}$; Hendri ${ }^{4}$; Andika ${ }^{5}$; Luqman ${ }^{6}$ \\ ${ }^{1,2,3,4,5}$ Program Studi Sarjana Teknik Mesin, Sekolah Tinggi Teknik PLN \\ ${ }^{6}$ Program Studi Sarjana Teknik Informatika, Sekolah Tinggi Teknik PLN \\ ${ }^{1}$ roswati@sttpln.ac.id
}

\begin{abstract}
ABSTRAK
Peningkatan standar kompetensi para guru dan siswa/i khususnya Sekolah Menengah Kejuruan sesuai dengan himbauan program kementrian Pendidikan untuk melakukan pelatihan bagi para guru dan siswa/i kejuruan. Pendidikan dan pelatihan ini merupakan salah satu bentuk media untuk mempersiapkan kompetensi para guru dan siswa/i kejuruan khususnya di SMK Negeri 3 Pariaman Sumatera Barat dengan merujuk kepada kurikulum 2013. Mitra kegiatan ini adalah SMK Negeri 3 Pariaman Sumatera Barat. Pelatihan ini diperuntukan bagi para guru dan siswa/i SMK Negeri 3 Pariaman Sumatera Barat khususnya di Program Studi Teknik Pendingin dan Tata Udara (TPTU). Pelatihan ini dilaksanakan dalam jangka waktu 3 (tiga) hari mulai tanggal 10 sampai dengan 12 Oktober 2018 dengan materi mengacu pada materi pembelajaran Kurikulum 2013 Sistem dan Instalasi Refrigerasi I. Setelah mengikuti pelatihan ini, maka diharapakan para Guru TPTU dapat mengimplementasikan pengetahuan dan keterampilannya untuk meningkatkan pengajaran berbasis kurikulum 2013 serta merawat peralatan sistem pendingin yang ada di Ruang Praktik Kerja dan Bengkel Program Studi Teknik Pendingin dan Tata Udara. Selain itu, para siswa/i mampu memahami dan memperkaya pengetahuan yang dimilikinya sebagai persiapan dalam menghadapi program magang serta sertifikasi ahli refrigerasi tingkat I di LSP SMK Negeri 3 Pariaman Sumatera Barat.
\end{abstract}

Kata kunci: Ahli refrigerasi tingkat I, sistem refrigerasi, Instalasi Refrigerasi

\begin{abstract}
Increasing the competency standards of teachers and students, especially vocational high schools in accordance with the appeals of the Ministry of Education program to conduct training for teachers and vocational students. This education and training is one form of media to prepare the competence of teachers and vocational students, especially in SMKN 3 Pariaman, West Sumatra by referring to the 2013 curriculum. The partners of this activity are SMKN 3 Pariaman, West Sumatra. This training is intended for teachers and students of SMKN 3 Pariaman, West Sumatra, especially in the Cooling and Air Conditioning Engineering Study Program. The training was conducted in 3 (three) days by referring to the 2013 Curriculum Learning System and Refrigeration Installation I material. After attending this training, Teachers were expected to be able to implement their knowledge and skills to improve curriculum-based teaching 2013 as well as caring for cooling system equipment in the Work Practice Room and Workshop in the Cooling and Air Conditioning Engineering Study Program. In addition, students are able to understand and enrich their knowledge in preparation for the internship program and certification of first-degree refrigeration experts in LSP SMKN3 Pariaman, West Sumatra.
\end{abstract}

Keywords: Level I refrigerants, refrigeration systems, refrigeration installations 


\section{PENDAHULUAN}

Penerapan kurikulum 2013 memiliki pendekatan yang dipergunakan dimana siswa/i diberanikan untuk mencari bahan sumber pembelajaran dari sumber belajar lain yang tersedia dan terbentang luas di sekitarnya, hal ini menuntut Peran guru sangat penting untuk meningkatkan dan menyesuaikan daya serap siswa. Guru dapat memperkayanya dengan kreasi dalam bentuk kegiatankegiatan lain yang sesuai dan relevan yang bersumberdari lingkungan sosial dan alam. hal ini menuntut agar para guru memiliki kompetensi yang mumpuni sehingga dapat mengarahkan siswa dengan baik sesuai tujuan dari kurikulum 2013.

SMK Negeri 3 Pariaman Sumatera Barat merupakan satu-satunya SMK yang menjalankan program latihan Militer. Dari pakaian seragam, rambut dan kegiatan latihan di atur seperti latihan militer. SMK Negeri 3 Pariaman Sumatera Barat merupakan SMK yang juga banyak peminatnya peserta didik dari lulusan SMP sederajat di dalam Kota Pariaman maupun di luar Kota Pariaman. Adapun jurusan SMK N 3 Pariaman adalah sebagai berikut : 1.Nautika Kapal Penangkap Ikan (NKPI), 2.Teknika Kapal Penangkap Ikan (TKPI), 3.Agribisnis Perikanan (AGP), 4.Teknik Komputer dan Jaringan (TKJ), 5.Teknik Pendingin dan Tata Udara (TPTU), 6.Rekaya Perangkat Lunak (RPL). Teknik pendingin dan Tata Udara merupakan Program Studi yang dibuka mulai TA. 2008/2009. Selain itu, SMK Negeri 3 Pariaman Sumatera Barat merupakan salah satu sekolah yang sudah menjadi Lembaga Sertifikasi Profesi (LSP) yaitu untuk tiap program studi yang dibuka. Untuk Program Studi TPTU LSP Skema KKNI Level II Pada kompetensi keahlian TPTU, Klaster : 1. Penanganan Sistem Refrigerator;2. Pemasanagn AC Split dan 3. Perawatan Perbaikan, akan tetapi dikarenakan adanya rotasi guru dari pusat sehingga kondisi saat ini mengakibatkan guru yang ditugaskan pada Prodi TPTU saat ini belum memiliki kompetensi yang cukup sehingga mengakibatkan tidak optimalnya kegiatan pengajaran yang diserap oleh siswa. Selain itu, peralatan yang ada di Ruang Praktik Kerja dan Bengkel menjadi tidak terawat sehingga banyak yang mengalami kerusakan sehingga tidak optimal untuk kegiatan pembelajaran. Berdasarkan hasil pengamatan studi lapangan, permasalahan yang dihadapi mitra adalah:

(1) SMK Negeri 3 Pariaman Sumatera Barat memiliki program studi TPTU yang perlu ditingkatkan kompetensinya, baik Para Guru maupun Para siswanya khususnya dalam bidang ahli refrigerasi tingkat I

(2) Para Siswa/i SMK Negeri 3 Pariaman Sumatera Barat belum memiliki kompetensi yang cukup khususnya dalam bidang praktek dan pemeliharaan TPTU untuk menghadapi program magang

(3) Tidak adanya guru dan teknisi yang memiliki kompetensi khusus di bidang TPTU sehingga Ruang Praktik Kerja dan Bengkel di Program Studi TPTU menjadi tidak terawat dan rusak sehingga kegiatan pembelajarn menjadi tidak optimal

Dari uraain diatas, maka pada kegiatan P2M STT-PLN memberikan pelatihan Ahli Refrigerasi tingkat I kepada para guru maupun siswa/i khususnya Program Studi TPTU yang bertujuan untuk meningkatkan kompetensi para guru dan siswa/I SMK Negeri 3 Pariaman Sumatera Barat sesuai cita-cita Kurikulum 2013. Pelatihan ini merupakan salah satu bentuk program pengabdian kepada masyarakat yang diselenggarakan oleh Prodi Sarjana Teknik Mesin. 


\section{METODE}

Metode pelaksanaan yang digunakan dalam pelaksanaan PKM ini adalah

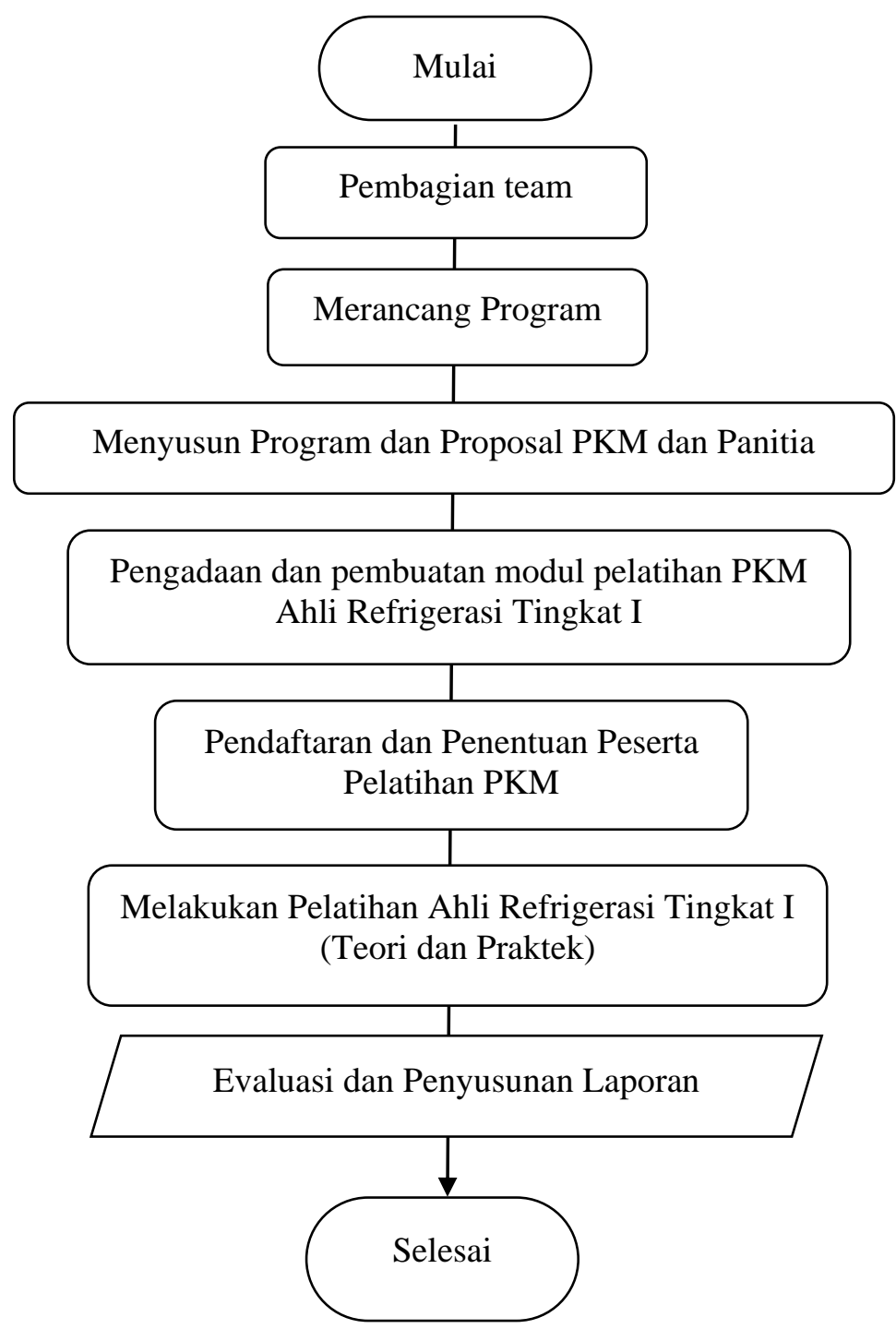

Gambar 1. Diagram Alir PKM

Pelatihan Ahli Refrigerasi tingkat I ini dilakukan selama 3 (tiga) hari yang diikuti oleh 48 peserta, dengan materi terdiri dari teori dan praktek untuk meningkatkan pengetahuan, keterampilan dan melatih para peserta dapat bekerja dalam suatu kelompok kerja sebagai persiapan program magang bagi para siswa/i SMK Negeri 3 Pariaman Sumatera Barat. Pada saat praktek maka dibagi menjadi beberapa kelompok agar kegiatan pelatihan menjadi lebih optimal. Adapun langkahlangkahnya adalah sebagai berikut:

Langkah 1: Peserta pelatihan diberikan teori tentang dasar-dasar sistem dan instalasi refrigerasi khususnya tingkat I

Langkah 2: Setelah mendapatkan teori maka para peserta pelatihan diberikan praktek dasar-dasar sistem dan instalasi refrigerasi khususnya tingkat I

Langkah 3: Peserta Pelatihan diminta untuk mempraktikkan secara langsung sistem refrigerasi mulai dari komponen-komponen peralatnnya maupun instalasi refrigerasi. 
Langkah 4: Setiap peserta secara berkelompok akan diuji secara langsung untuk mengetahui kompetensinya dalam sistem dan instalasi sistem Refrigerasi Tingkat I

Langkah 5: Para Peserta dan Tim P2M melakukan evaluasi dari hasil pelatihan dan melakukan assessment sederhana terhadap peralatan di Ruang Praktik Kerja dan Bengkel TPTU khususnya yang mengalami kerusakan.

Secara garis besar materi yang disampaikan pada pelatihan mengacu pada materi sistem dan instalasi Refrigerasi Tingkat I Kurikulum 2013, adalah:

1) Menguraikan elemen Dasar dan Prinsip Refrigerasi
a) Penerapan Sistem Satuan
b) Pengukuran Tekanan dan Suhu Zat di dalam Sistem Tertutup
c) Sistem Termodinamika
d) Prinsip Refrigerasi

2) Menguraikan Komponen Utama Unit Refrigerasi
a) Unit Refrigerasi Domestik
b) Kompresor
c) Kondensor
d) Evaporator
e) Throttling Device
f) Strainer
g) Defrost Heater
h) Siklus Refrigerasi Kompresi Gas

3) Menguraikan refrigeran dan Isu Lingkungan
a) Kerusakan Lapisan ozon Startosfir
b) Pemanasan Global
c) Refrigeran
d) Oli Refrigeran

4) Melakukan Pekerjaan Pemipaan Refrigerasi
a) Pipa Tembaga
b) Pipa Aluminium
c) Pipa Baja
d) Pipa Fleksibel
e) Soldering dan Flarring Fitting
f) Peralatan Kerja Pipa
g) Kerja Pipa

5) Sistem Kelistrikan

\section{HASIL DAN PEMBAHASAN}

Sesuai dengan rancangan, kegiatan diawali dengan brain storming dengan Pimpinan SMK Negeri 3 Pariaman Sumatera Barat yang dilaksankan pada 9 Oktober 2019 untuk mengetahui tingkat kompetensi dari para peserta, yang terdiri dari Guru dan Para siswa/i SMK Negeri 3 Pariaman Sumatera Barat dari pertemuan ini diketahui beberapa permasalahan yang dimiliki oleh SMK Negeri 3 Pariaman Sumatera Barat, diantaranya kompetensi para guru yang masih kurang yang berdampak pada kurang optimalnya kegiatan pembelajaran kepada siswa serta mengakibatkan terbengkalainya peralatan di Ruang Praktik Kerja dan Bengkel Teknik Pendingin dan Tata Udara di SMK Negeri 3 
Pariaman Sumatera Barat, sehingga diperlukan pelatihan dasar Ahli Refrigerasi Tingkat I untuk meningkatkan kompetensi para guru, selain itu para siswa/i juga memerlukan kompetensi yang sama sebagai persipan para siswa/i untuk menghadapi kegiatan magang dan sertifikasi ahli refrigerasi. Selain itu, pada hari-1 digunakan juga sebagai persiapan untuk pelaksanaan pelatihan pada tanggal 10 sampai dengan 12 Oktober 2018. Adapun foto-foto kegiatan lainnya dimaksud adalah sebagai berikut:

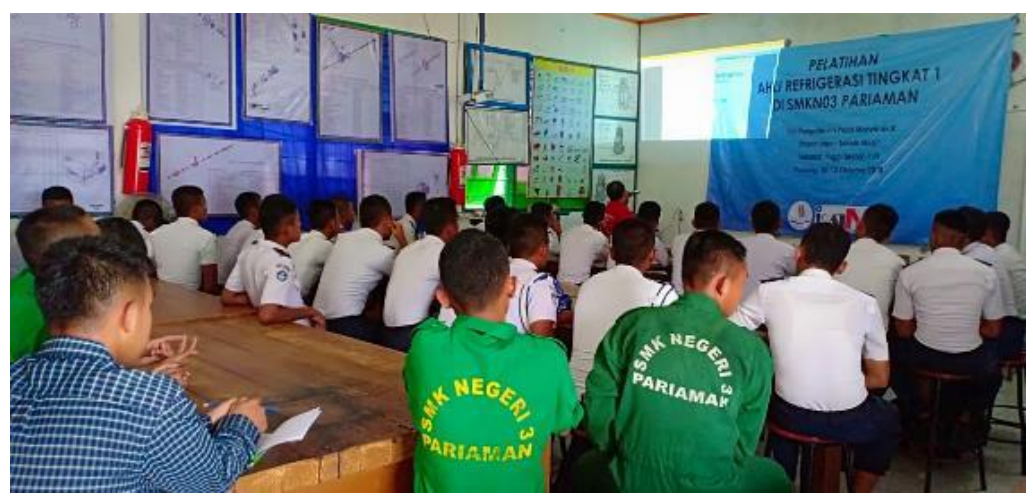

Gambar 2. Pemaparan Teori Ahli Refrigerasi Tingkat I oleh Tim P2M

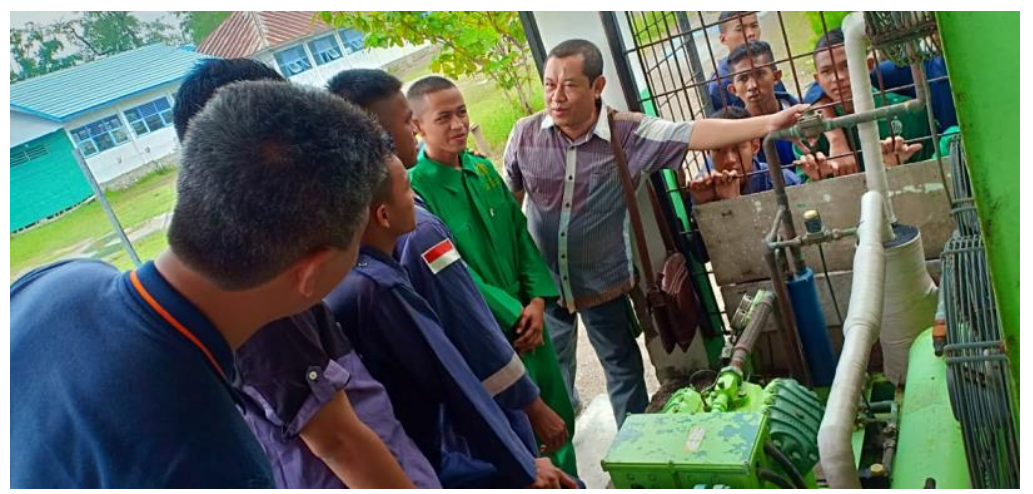

Gambar 3. Pengenalan Peralatan dan Komponen Sistem Refrigerasi Tiap Kelompok

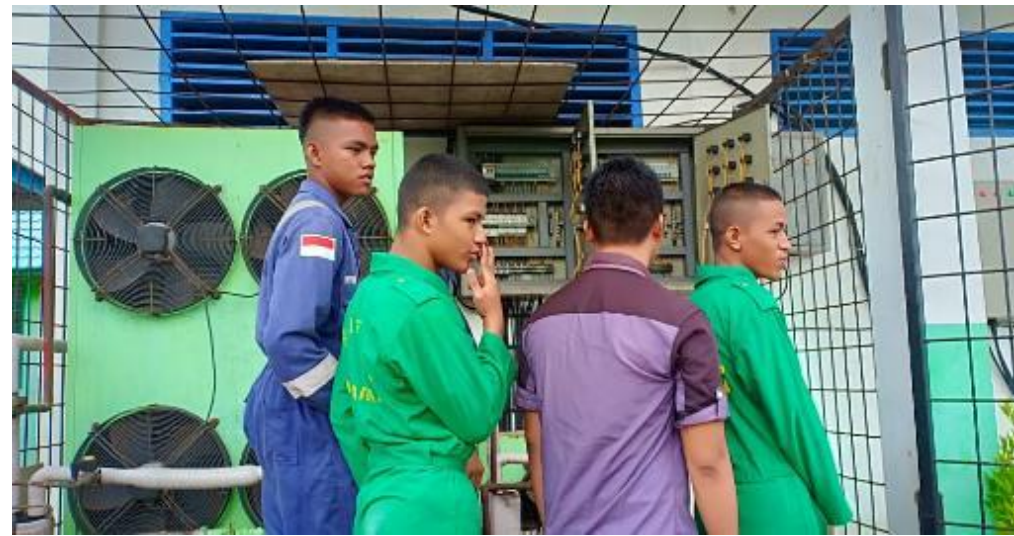

Gambar 4. Pelaksanaan Post Test Praktek 

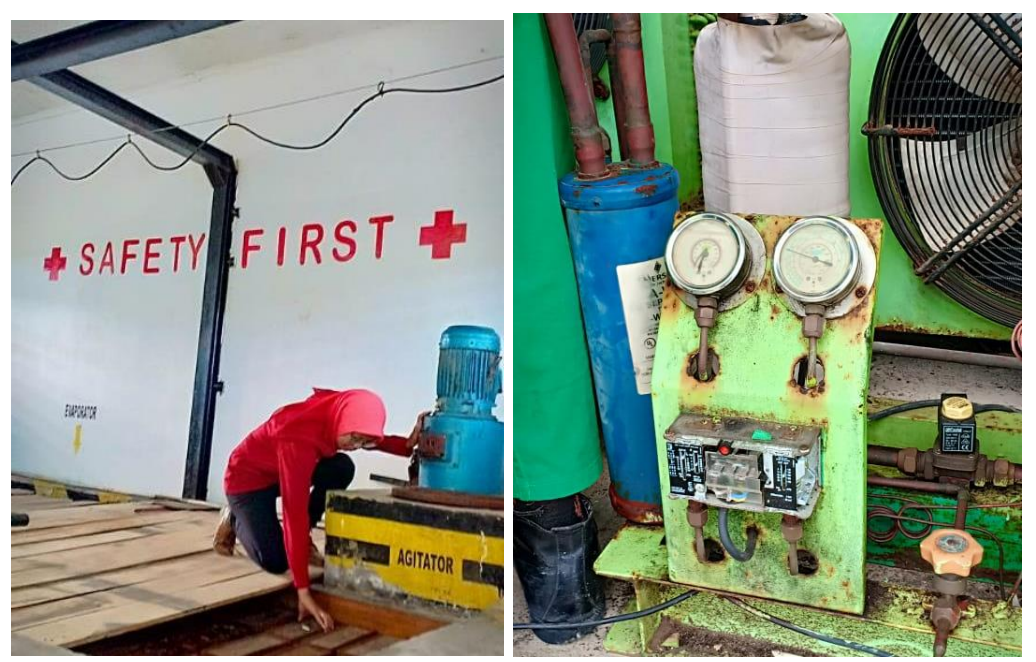

Gambar 5. Assesment Peralatan di Ruang Kerja Praktik dan Bengkel TPTU

Kegiatan pres test dan posttest ini dilakukan untuk mengetahui seberapa besar penyerapan materi pembelajaran yang diterima oleh peserta, adapun metode yang digunakan pada pretest dan posttest ini adalah tes praktek. Fokus dari materi pretest dan post ini adalah untuk mengetahui tingkat pemahaman peserta tentang dasar-dasar refrigerasi dan komponen sistem refarigerasi serta tata cara perawatan mesin pendingin khususnya yang ada di Ruang Praktik dan bengkel di Prodi TPTU. Berdasarkan hasil posttest maka bagi peserta terbaik diberikan merchandise dari Tim P2M Sekolah Tinggi Teknik-PLN. Untuk mengukur kompetensi peserta pelatihan dalam memahami prinsip Sistem Refrigerasi, maka para peserta diberikan pertanyaan tentang prinsip sistem refrigerasi Cold Storage dan Pabrik Es yang ada di Ruang Praktek dan Bengkel TPTU, adapun hasil pretest dan posttest ditunjukan sebagai berikut:

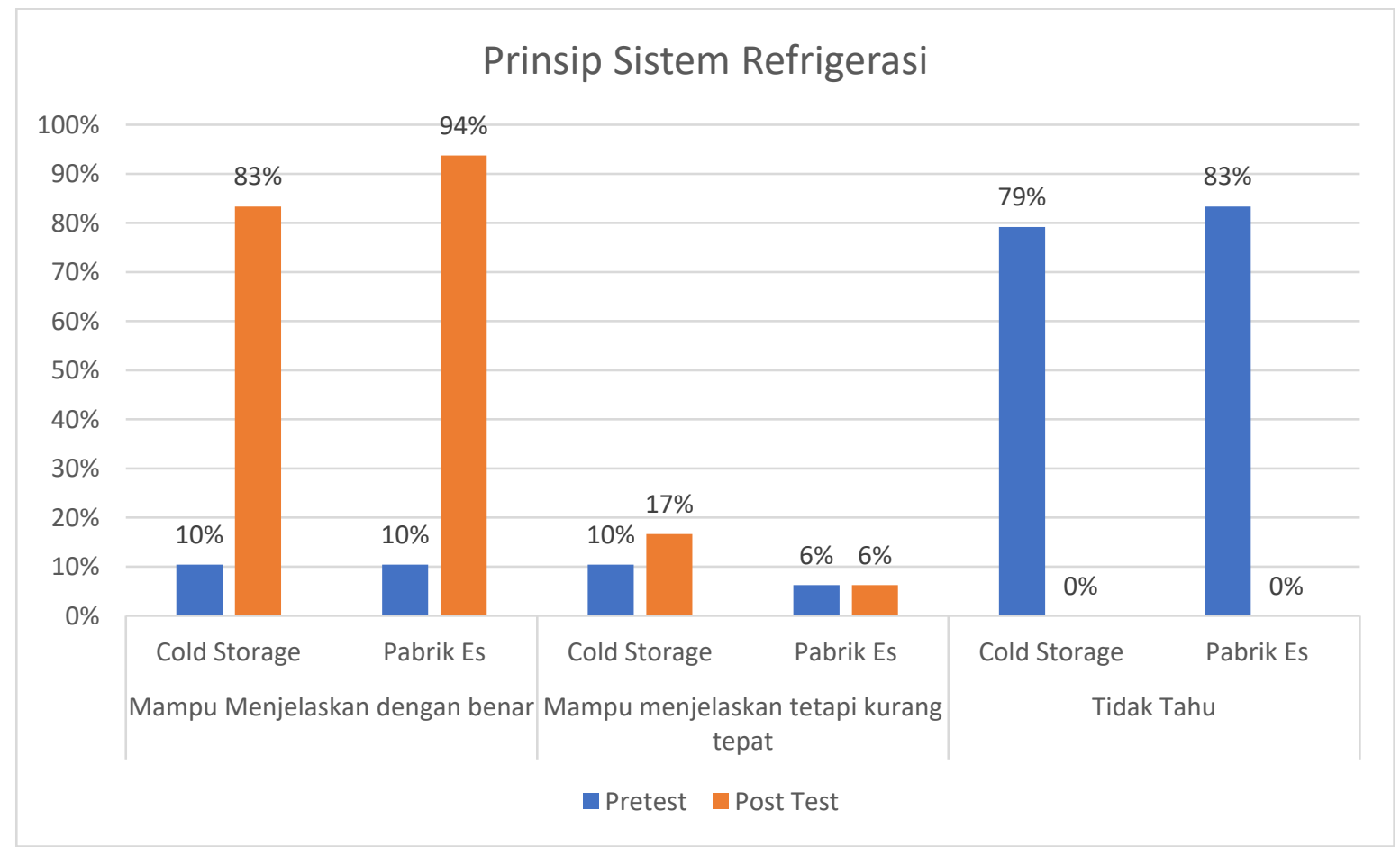

Gambar 6. Pemahaman Terhadap Prinsip Sistem Refrigerasi Cold Storage \& Pabrik Es TPTU 
Berdasarkan gambar-gambar diatas, terlihat bahwa peserta pelatihan mampu menjelaskan prinsip sistem refrigerasi Pabrik Es dari 10\% menjadi 94\% setelah peserta mengikuti pelatihan, untuk Cold Storage meningkat dari $10 \%$ menjadi $84 \%$. Dengan adanya pelatihan ini maka peserta pelatihan seluruhnya mampu mengetahui prinsip kerja dari sistem refrigerasi baik untuk studi kasus Cold Storage maupun pabrik Es.

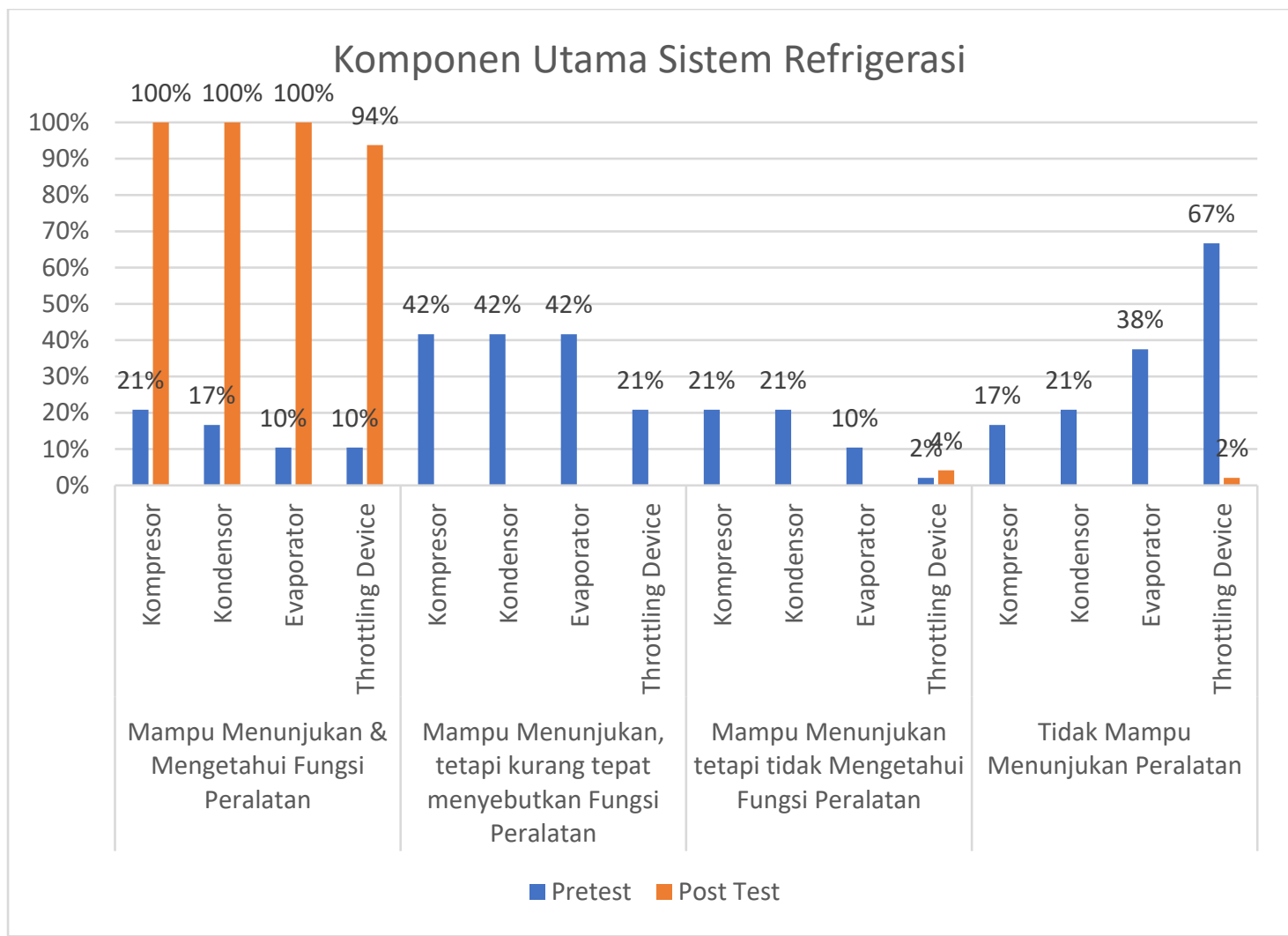

Gambar 7. Pemahaman Terhadap Komponen Utama Sistem Refrigerasi

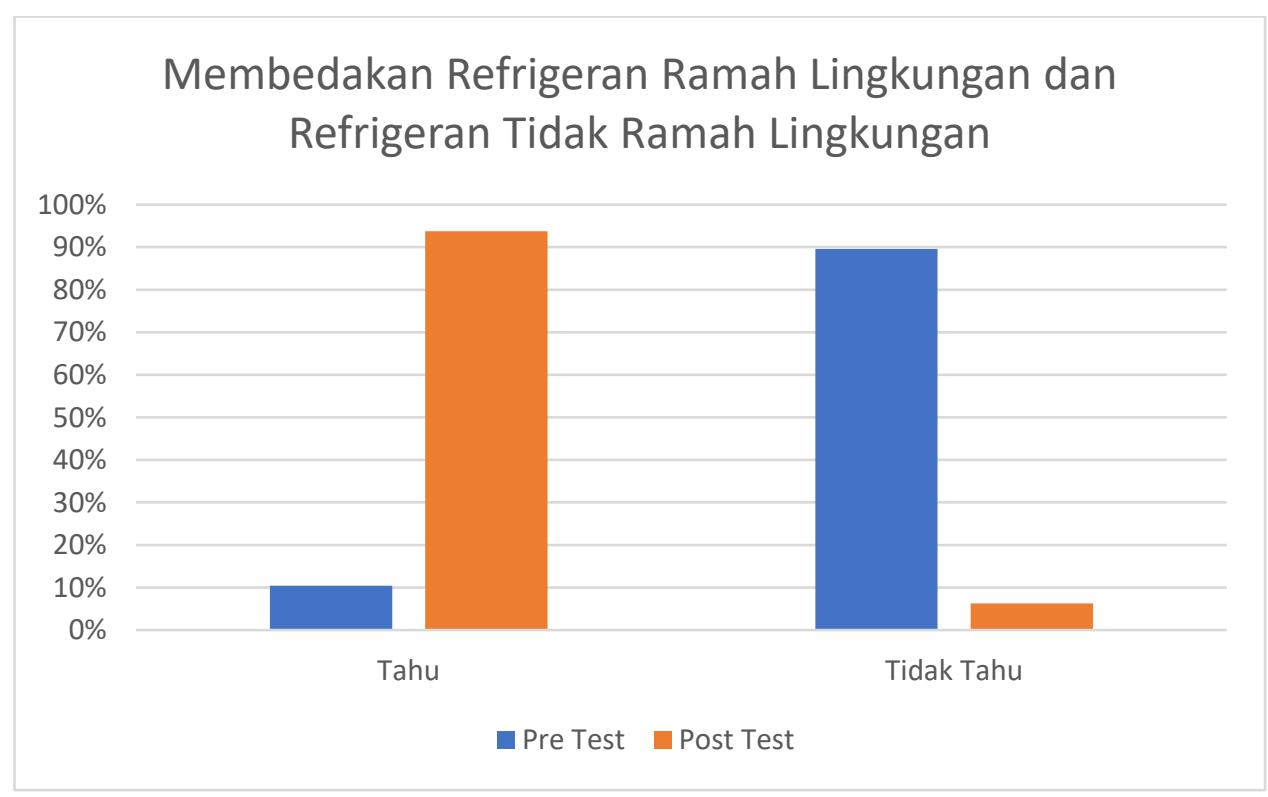

Gambar 8. Pemahaman Terhadap Refrigeran 
Berdasarkan gambar diatas, maka terlihat bahwa dengan adanya pelatihan Ahli Refrigerasi Tingkat I ini, maka pengetahuan terhadap komponen utama sekaligus fungsinya menjadi meningkat hingga 100\% untuk kemampuan dalam menunjukan maupun menyebutkan fungsi dari komponen kompresor, kondensor dan evaporator.

Sub pembahasan dalam pelatihan ini adalah Refrigeran, dimana pengetahuan terhadap karaktersitik dari refrigerant sangat diperlukan bagi calon ahli refrigerasi tingkat 1 . Salah satu yang penting dalam isu refrigerant ini adalah refrigerant dan dampaknya terhadap lingkungan, sehingga para peserta diberikan pengetahuan dasar tentang refrigerant yang berbahaya serta penggantinya berupa refrigerant ramah lingkungan. Diharapkan dengan adanya pengenalan ini, maka para calon ahli refrigerasi ini mampu mengaplikasikannya dalam kehidupan sehingga akan memiliki dampak yang baik terhadap lingkungan. Berdasarkan hasil posttest, maka pengetahuan para peserta terhadap refrigerant ramah lingkungan meningkat dari $10 \%$ menjadi $94 \%$.

Bahan kajian lainnya pada pelatihan ini yaitu Instalasi pemipaan dan sistem kelitrikan dalam sistem refrigerasi. Peningkatan pengetahuan para peserta terhadap hal tersebut dapat dilihat dalam gambar-gambar dibawah ini:

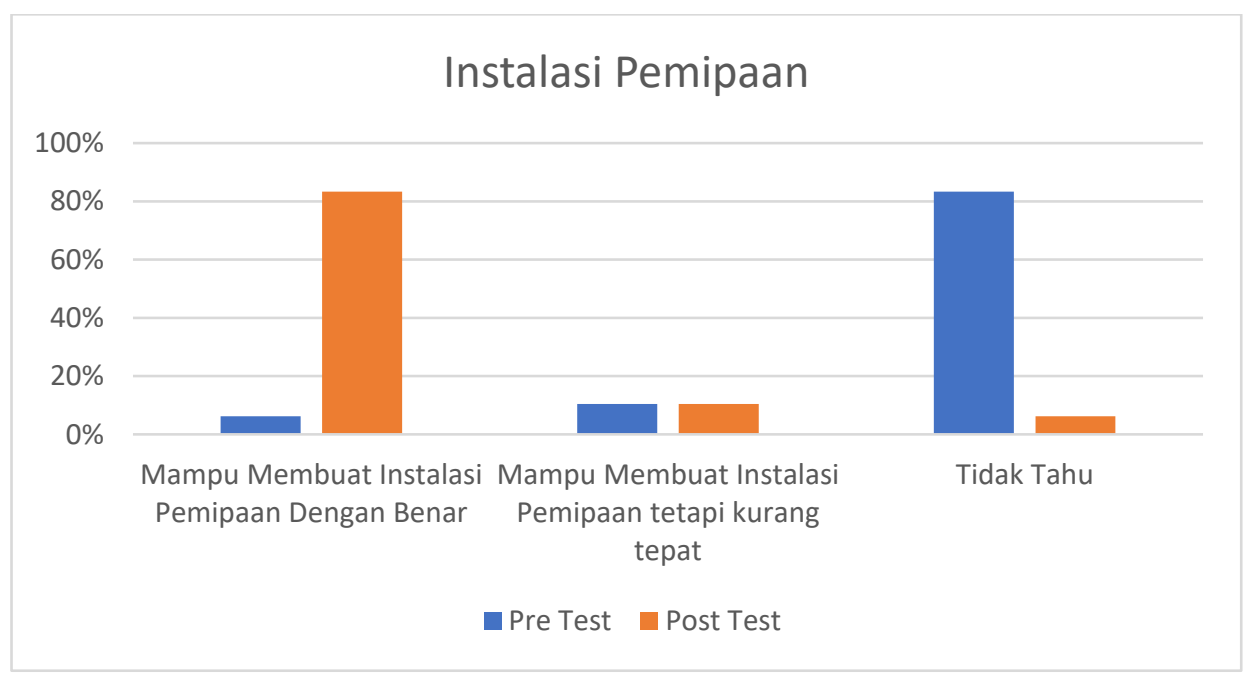

Gambar 9. Pemahaman Terhadap Instalasi Pemipaan

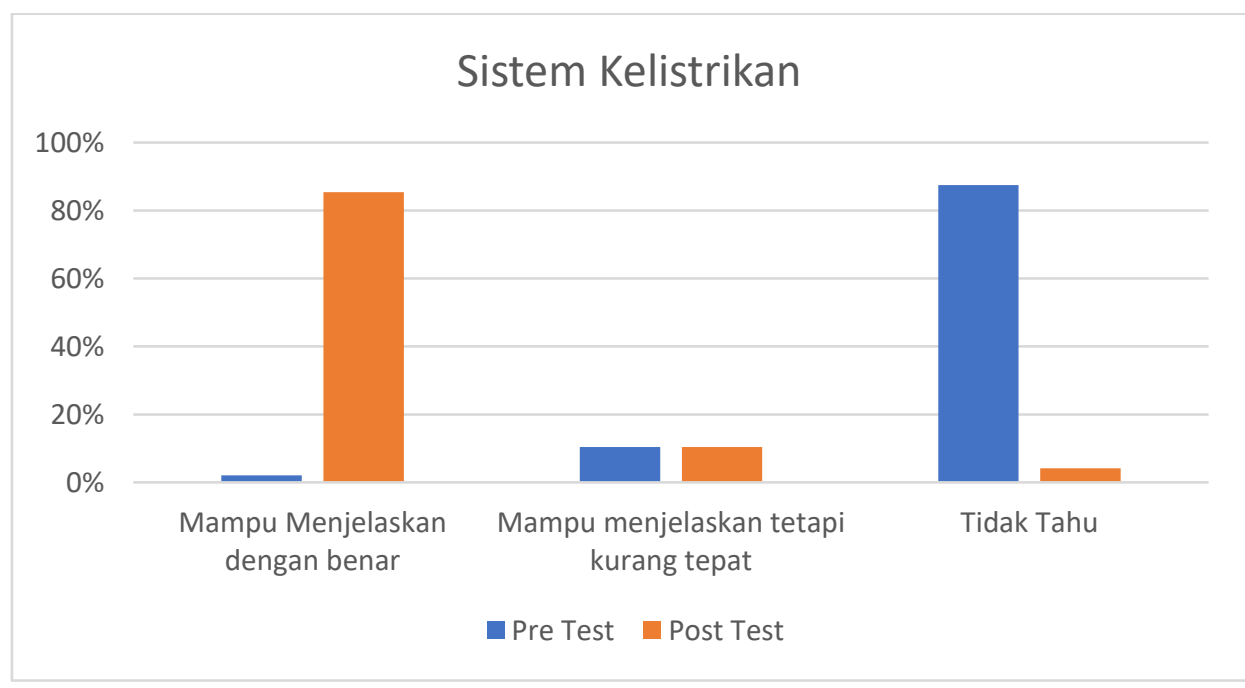

Gambar 10. Pemahaman Terhadap Sistem Kelistrikan 
Berdasarkan gambar diatas, terlihat bahwa pengetahuan peserta terhadap instalasi pemipaan maupun sistem kelistrikan menjadi meningkat. Untuk pengetahuan isntalasi pemipaan peningkatan dari $6 \%$ menjadi $83 \%$ para peserta mampu membuat sketsa pemipaan baik untuk cold storage maupun pabrik es di Ruang Praktik Kerja dan Bengkel TPTU dan 2\% menjadi 85\% untuk pengetahuan para peserta dalam menjelaskan sistem kelistrikan pada studi kasus cold storage di Ruang Praktik Kerja dan Bengkel TPTU SMK Negeri 3 Pariaman Sumatera Barat.

\section{KESIMPULAN}

Mengacu pada rancangan kegiatan dan berdasarkan dari hasil kegiatan dapat disimpulkan bahwa Pelatihan Ahli Refrigerasi Tingkat I bagi Para Guru dan Siswa/i SMK Negeri 3 Pariaman Sumatera Barat secara positip berdampak pada peningkatan kompetensi dan keahlian guru dan sisw/i di bidang sistem Refrigerasi sehingga lebih siap dalam menghadapi program magang serta ujian sertifikasi ahli refrigerasi.

\section{SARAN}

STT-PLN perlu lebih menggalakkan dan meingkatkan program sosialisasi pemakaian refrigerant ramah lingkungan, khususnya bagi masyarakat dan siswa/i SMK Kejuruan Teknik Pendingin dan tata Udara baik yang ada disekitar kampus maupun didaerah-daerah lainnya..

\section{UCAPAN TERIMA KASIH}

Dengan terlaksannya kegiatan ini, Tim P2M Departemen Teknik Mesin STT-PLN mengucapkan terima kasih kepada : Pimpinan STT-PLN ; Indrianto, S.Kom, MT. selaku Kepala LPPM STT PLN ; Hengki Sikumbang, SE, MMSI selaku Kasie P2M LPPM STT PLN dan Drs.Raffudin, M.Pd. T selaku Kepala SMK Negeri 3 Pariaman Sumatera Barat atas bantuannya yang tidak ternilai sehingga semua rencana kegiatan P2M pada semester Gasal Tahun Akademik 2018/2019 ini terlaksana dengan baik.

\section{DAFTAR PUSTAKA}

[1] 2018. [Online]. Available: http://smkn3pariman.blogspot.com/ diakses 28 Januari 2019

[2] 2018. [Online]. Available: www.smkn3pariaman.sch.id. Diakses 28 September 2018

[3] Direktorat Pembinaan SMK Direktorat Jendarl Pendidikan Dasar dan Menengah, Sistem dan Instalasi Refrigerasi I, Kementrian Pendidikan dan Kebudayaan, 2013. 